\title{
Letters
}

\section{Low-dose ketamine in the prehospital setting}

We read the recent CMAJ article on ketamine for the treatment of acute pain by Silverstein and colleagues with great interest. ${ }^{1}$ They note that low-dose ketamine is an effective analgesic in several clinical settings, including anesthesiology, critical care, pain management and emergency medicine. ${ }^{2}$

We wish to bring attention to emerging literature that effective and safe administration of low-dose ketamine can be provided to adult and pediatric patients by paramedics in the prehospital setting. ${ }^{3}$ Importantly, a joint position statement supporting the prehospital use of ketamine as an analgesic in acute trauma patients has recently been published by several American organizations, including the American College of Surgeons Committee on Trauma, the American College of Emergency Physicians and the National Association of Emergency Medical Services Physicians. ${ }^{4}$

Given the limitations of opioids, nonopioid analgesia is clearly needed in the prehospital environment. Examples include high-acuity trauma patients at risk for (or exhibiting) hemorrhagic shock or respiratory compromise, patients in severe pain with known allergies to morphine and fentanyl, and patients with a history of narcotic use disorder who do not wish to be administered opioids or who are receiving treatment with buprenorphine-naloxone.

Medical directives for ketamine analgesia are already in place for paramedic use in several Canadian provinces, and Ontario is in the process of doing likewise. We applaud this recent addition to the paramedic scope of practice for the management of severe pain.

\section{Alvin Yuhalogarasan}

Advanced care paramedic, Toronto Paramedic Services, Toronto, Ont.

\section{Chris Barclay}

Advanced care paramedic, Toronto

Paramedic Services, Toronto, Ont.

\section{P. Richard Verbeek MD}

Physician, Sunnybrook Health Science

Centre, Toronto, Ont.
Cite as: CMAJ 2022 February 7;194:E171. doi: 10.1503/cmaj.80599

\section{References}

1. Silverstein WK, Juurlink DN, Zipursky JS. Ketamine for the treatment of acute pain. CMAJ 2021;193:E1663.

2. Schwenk ES, Viscusi ER, Buvanendran A, et al. Consensus guidelines on the use of ketamine infusions for acute pain from the American Society of Regional Anesthesia, the American Academy of Pain Medicine, and the American Society of Anesthesiologists. Reg Anesth Pain Med 2018;43:456-66

3. Sobieraj DM, Martinez BK, Miao B, et al. Comparative effectiveness of analgesics to reduce acute pain in the prehospital setting. Prehosp Emerg Care 2020;24:163-74.

4. Morgan MM, Perina DG, Acquisto NM, et al. Ketamine use in prehospital and hospital treatment of the acute trauma patient: a joint position statement. Prehosp Emerg Care 2021;25:588-92.

\section{Competing interests: None declared.}

Content licence: This is an Open Access article distributed in accordance with the terms of the Creative Commons Attribution (CC BY-NC-ND 4.0) licence, which permits use, distribution and reproduction in any medium, provided that the original publication is properly cited, the use is noncommercial (i.e., research or educational use), and no modifications or adaptations are made. See: https://creativecommons.org/ licenses/by-nc-nd/4.0/ 